An ASABE Meeting Presentation

Paper Number: 1009793

2950 Niles Road, St. Joseph, MI 49085-9659, USA

269.429.0300 fax 269.429.3852 hq@asabe.org www.asabe.org

\title{
Use of Reflective PAR Mulches to Enhance Winter-time Greenhouse Strawberry Production
}

\author{
George E. Meyer \\ Biological Systems Engineering \\ Ellen T. Paparozzi \\ Agronomy and Horticulture \\ Elizabeth A. Walter-Shea \\ School of Natural Resources \\ Stacy A. Adams \\ Agronomy and Horticulture \\ University of Nebraska, Lincoln, NE \\ Written for presentation at the \\ 2010 ASABE Annual International Meeting \\ Sponsored by ASABE \\ David L. Lawrence Convention Center \\ Pittsburgh, Pennsylvania \\ June 20 - June 23, 2010
}

\begin{abstract}
Photosynthethically-active-radiation (PAR) has long been used by horticultural specialists and crop modelers to characterize the quantity and quality of light conducive to plant growth and development. The spatial distribution of light within a double-polyethylene glazed plastic Quonset greenhouse can be quite variable and diffuse throughout the photoperiod, especially at low sun angles in the northern regions of the United States. Previous literature has reported $10-35 \%$ increase in canopy lighting using reflective plastics under various plants. $A$ study was undertaken to evaluate the productivity of fourteen strawberry cultivars in a campus Quonset house during the winter months. Modified field of view LiCOR ${ }^{T M}$ PAR reflectance sensors, full hemispherical PAR incident sensors, and infrared thermocouple sensors (IRT/C) were mounted over gravel and five different color plastic backgrounds. PAR and mulch temperatures were recorded for several months using a wireless LabVIEW ${ }^{\text {TM-based sensor }}$ network within the greenhouse. Weather and the greenhouse environment were also monitored. The use of background reflective plastics or so-called reflective mulches to increase $P A R$ and to capture heat within cap-mats was also studied. It was experimentally found that
\end{abstract}


several of these cultivars will bear significant fruit and could be economically productive during winter.

Keywords. Greenhouse, strawberries, photosynthetically active radiation, reflective mulches, plastic

\section{Introduction}

Nebraska - the heartland of America is known nationally and internationally for its agricultural field crop production during spring, summer, and fall. However, what is not well-understood is that some of the sunniest days of the year occur during the winter months, solar energy which could be utilized for controlled environment agriculture (CEA). With uncertain transportation costs, concerns about imported food safety, human health/obesity issues, and the need to improve local economies, increasing local production of fresh fruits and vegetables would be a logical step for Nebraska CEA. The following overall project aims have been proposed:

(a) To create and test a cost effective and energy efficient prototype system for CEA winter fruit and vegetable production.

(b) To evaluate product quality and marketability.

To accomplish these aims, a typical Quonset, double polyethylene commercial style production greenhouse located on the East Campus of UNL was modified and used for prototype studies. Features of a Quonset house include easy construction and cost-accounting as do-a-yourself venture, efficient heating and cooling, hand-constructed benches, potential for improved utilization of photosynthetically-active-radiation (PAR) using reflective mulches, and an efficient watering/fertigation, possibly with capillary mat systems. The prototype greenhouse was fully instrumented to monitor temperature, humidity, light quantity and quality, energy, water, and fertilizer utilization.

An important issue that arises when growing plants in Nebraska greenhouses during the winter is whether adequate light is available for successful flower and/or fruit production. During the winter months, Nebraska is fortunate to receive more bright sunny days than cloudy ones, because of dry arctic air and weather fronts. Heating costs become another concern with cold temperatures. However, a principle criticism of proposals to grow flowers and food profitably during the winter have suggested that light would be an important limiting factor.

Therefore, a special project was undertaken this past winter season to test colored plastics to determine whether they could increase the amount of reflected light to plants in a greenhouse. This was followed by a production study with the most promising plastic mulch. Decoteau, et al (1989) studied mulch surface color on fresh market tomatoes and found it to affect the productivity of tomatoes. Their results indicated that surface mulches may affect the microclimate (spectral quality and quantity of light and soil surface temperature). Black plastics tended to increase soil surface temperature the most, while white surface plastics had cooler temperatures. Csizinszky, at al (1995) conducted a field study on the effect of six mulch colors: blue, orange, red, aluminum, yellow, and white (fall) or black (spring), on fruit yields and insect vectors of Sunny' tomato (Lycopersicon esculentum Mill.). Reduced numbers of whiteflies on the orange and aluminum mulches delayed virus symptom development and increased yields. 
They also conducted a spectral study on mulch reflectance. Aluminum had the highest reflectance, while black the lowest. Gough (2001) studied the affect of plastic mulch color on the lateral development of root architecture of 'Sweet Banana' pepper [Capsicum annuum L. (Grossum Group)]. The highest number of lateral roots was produced under silver mulch, intermediate numbers under clean cultivation and black mulch, but the fewest roots occurred under red mulch. Colored mulches influenced the total number of adventitious and lateral roots but not the root system architecture of pepper plants. Greer and Dole (2003) found that yields of various vegetables were increased when grown on aluminum foil or aluminum-painted plastic mulch. A difficulty of these past studies was to discern whether the mulch affected the PAR back reflected into the lower canopy or the soil temperatures. The studies also suggested that brightness rather than color was more affective. Brightness is a very general term and could relate to both short wave and long wave radiation. Long wave reflection could increase canopy temperatures.

Black plastics utilized as mulches could also possibly affect the amount of stored heat within the structure once the sun goes down. As a result of more photosynthetically-active-radiation and stored heat, the grower might entertain a more feasible and profitable winter grown crop. Clear plastics were found to allow PAR to penetrate to the soil surface under the plastic and promote weed growth. Color may also affect the attractiveness of insects such as white flies. Another factor would be the amount of vegetative plant material or leaf-area-index (LAI) that would actually intercept light energy directly and not allow penetration to the mulch below the canopy. Yet, another question is how do plants in pots work with plastic mulch and an irrigation or fertigation system.

Thus, a study was undertaken to assess the reflective and transmissive properties of commercial plastic films that might be used as mulches. The objectives of this study were to determine the photo reflective properties of four plastic mulches and how these might affect the production of greenhouse strawberries. A second objective was to actually grow a crop using the selected plastic mulch.

\section{Materials and Methods}

The reflective plastic mulch study was conducted during November and December 2009 at Quonset Greenhouse 68 on the East Campus of the University of Nebraska. This greenhouse was controlled by a Groton Elite climate controller (ACME, Inc, Muskogee, OK). Plastics were set onto the gravel floor of this double polyethylene greenhouse. Four colored polyethylene films (red, black, dark olive; 1 mil thick) and (4 mil and 6 mil white polyethylene) were procured from Ken-Bar Manufacturing (Peabody, MA). Three polyethylene film strips were placed the width of the house. The experiment design was a simple block design with three - 6 foot wide strips of polyethylene film alternating with $6 \mathrm{ft}$ widths of the exposed greenhouse gravel base floor of the greenhouse (Figures 1, 2 and 3). Over each polyethylene and gravel section were suspended LiCor 190SA Quantum sensors (Lincoln, NE) for measuring direct and reflected PAR (umoles $/ \mathrm{m}^{2} / \mathrm{s}$ ). The spectral response of the LiCor sensor is shown in Figure 4. Also mounted were Omega OS36SM (Omega Engineering, Stamford, CT) type-K infrared temperature sensors (IRT/c's) to measure soil gravel and polyethylene film temperatures. 

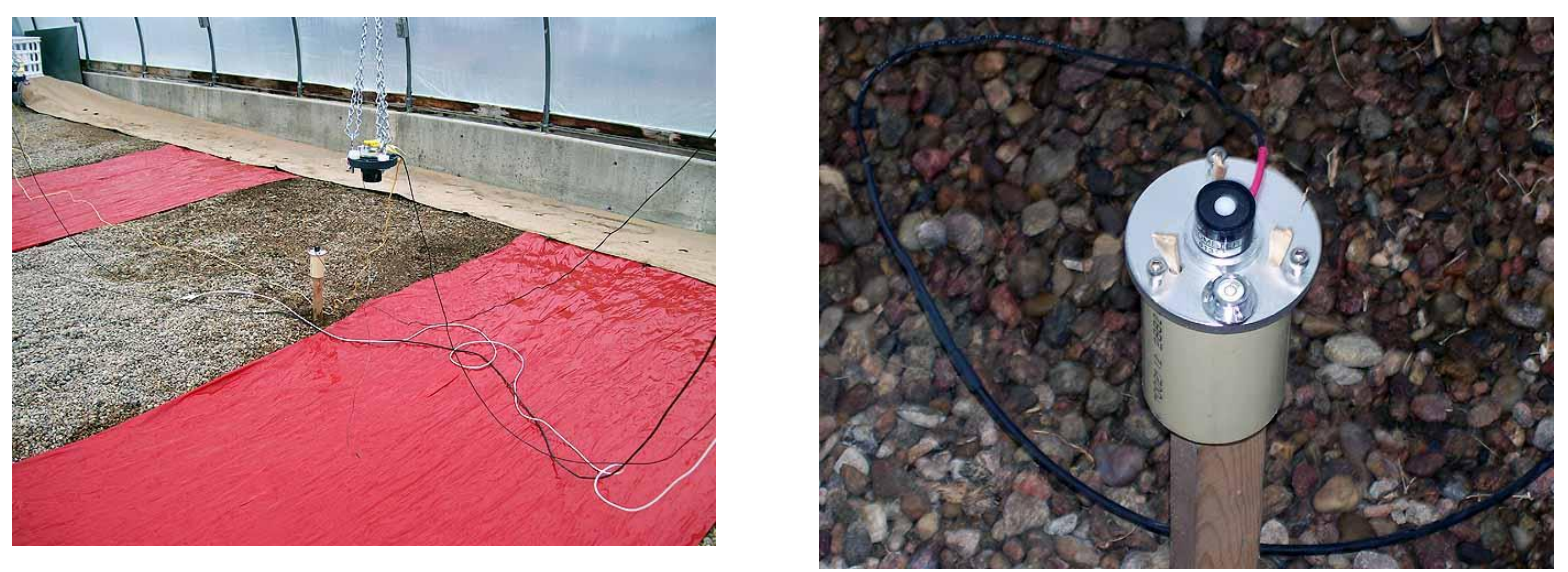

Figure 1. Close-up of LiCor PAR Sensors. One incident and one reflective PAR over red plastic.

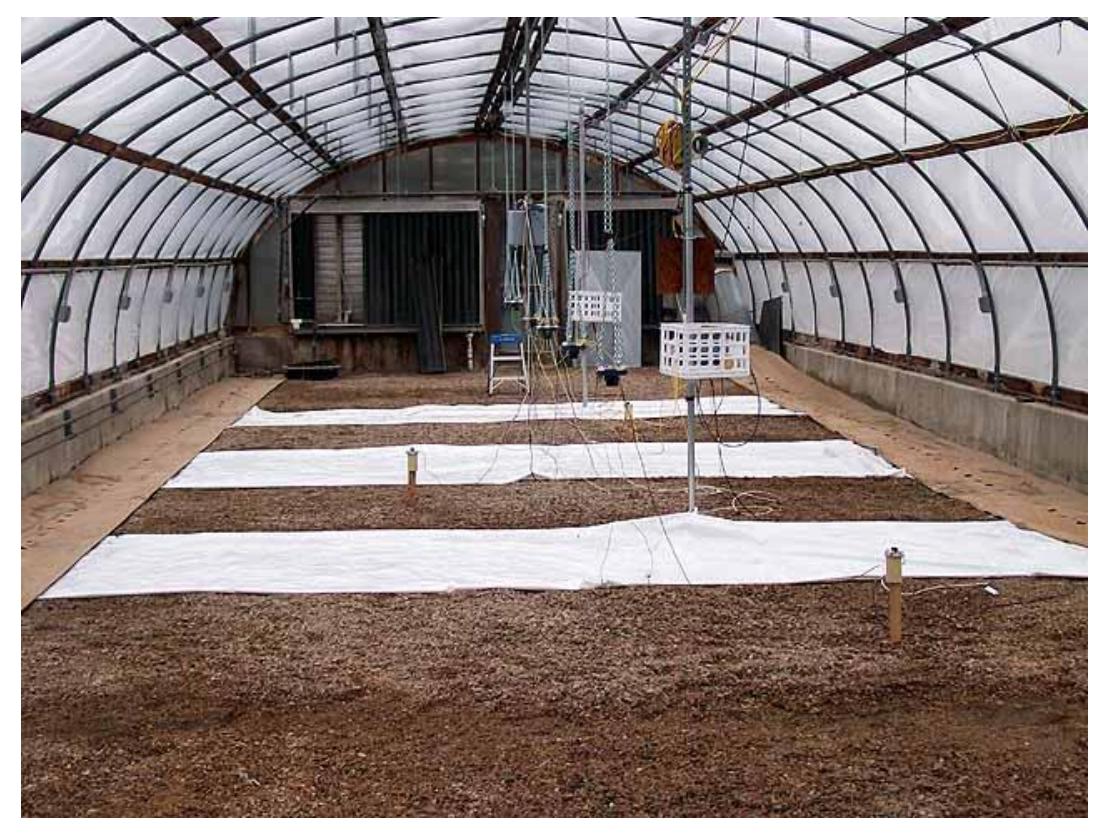

Figure 2. Reflective Mulch and Surface temperature Study with 6-mil white plastic.

Each LiCor reflectance sensor was mounted downward to a surface of a one square meter area of the plastic or gravel surface through a short PVC tube to capture the reflected energy only from this surface. (LiCor PAR sensors actually measure hemispherical incoming radiation and thus can intercept measure light reflected from other parts of the house). Incident PAR was measured with upward facing LiCor sensors for full incoming hemispherical energy. Total radiation was also measured with LiCor pyranometers, both under the glazing and outside (watts $/ \mathrm{m}^{2}$ ) the greenhouse. Each color was left in place and measured for about 7 to 14 days. Greenhouse air temperatures $\left({ }^{\circ} \mathrm{C}\right)$, relative humidity \%), and greenhouse heating and cooling events and times were also recorded.

A wireless Measurement and Computing WLS-TEMP 24-bit (Norton, MA) and a USB LabJack U12 (Denver, CO) 12-bit data loggers were used to take all of the measurements. The system 
was implemented using LabVIEW $8.2 \AA$ software (National Instruments, Austin, TX). Measurements were recorded every 10 minutes to an Excel File, along with real-time graphs and alarm indicators as part of the LabVIEW model. A dedicated Windows XP greenhouse computer located in an air-cooled cabinet was connected to the campus internet system via a Caralys ${ }^{\circledR} 2940$ router and could be easily visited by password protected remote console from the office or world-wide. A web-cam was also installed in the greenhouse.

The LabVIEW program displayed and recorded all heating and cooling events for the greenhouse. Sufficient data was collected to be used for calculated greenhouse heat losses and efficiencies (ASABE engineering standard, EP406.3). The LabVIEW Front Panel of the reflective mulch program shown in Figures $5 \mathrm{a}$ and $5 \mathrm{~b}$. The layout of the reflective zones and current data values were shown on a tab container structure. All solar calibration coefficients and psychrometric calculations were included the program.

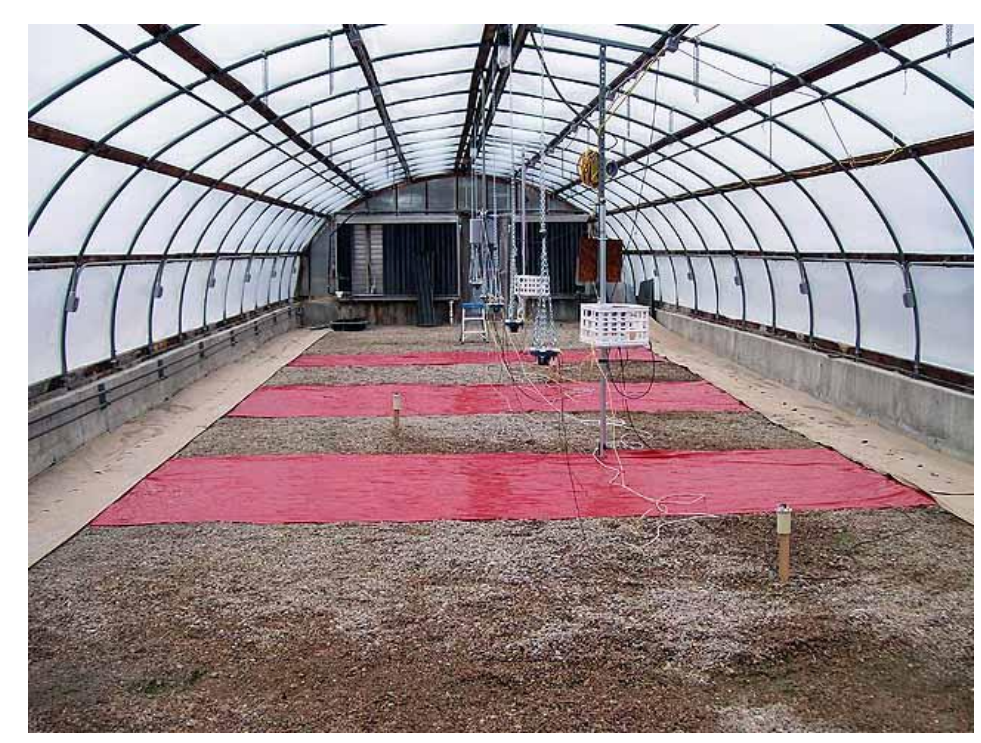

Figure 3. Reflective Mulch and Surface temperature Study with 4-mil red plastic.

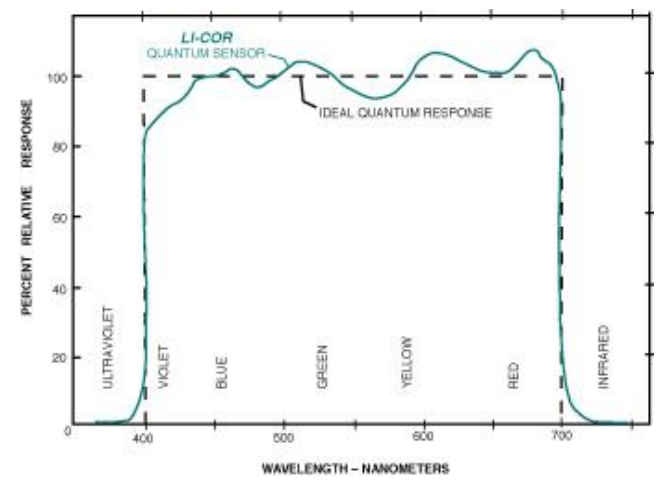

Figure 4. Spectral response of LI-COR Quantum Sensors vs. Wavelength versus an Ideal Quantum Response (Courtesy of LiCor Biosciences, inc.). 


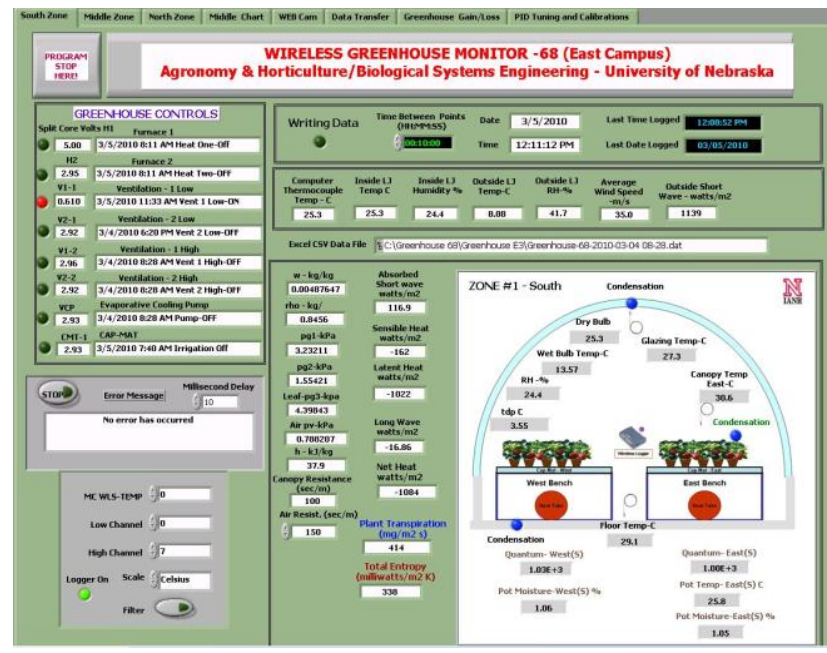

Figure 5a. Left Front Panel of LabVIEW Greenhouse Events and South Logger Panel.

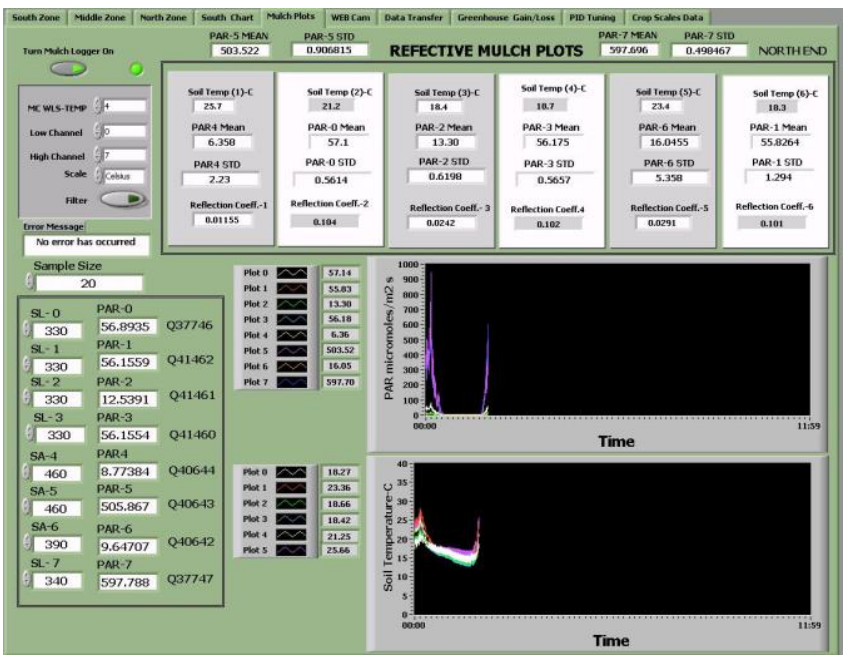

Figure 5b. Mulch LabVIEW Logging Panel.

An independent integrating-sphere light study was used to validate the greenhouse reflectance and transmittance results obtained for each film and the gravel surface. Small representative samples of the polyethylene films were mounted in a LiCor integrating sphere port with a SE590 spectroradiometer (Spectron, inc., Denver, CO) shown in Figure 6. Reflectance of the gravel surfaces was measured in situ in the greenhouse. The Spectron instrument is a diffraction-grading device which measures luminance from reflection or transmission from 400 to 1100 nanometers wavelength. The integrating sphere uses a halogen light source (peak about 800 nanometers) and conserves all light energy within a barium sulfate, interior painted sphere. All reflectance and transmission readings are adjusted for a dark or stray light prior to the film measurement. The Spectron measurements will generally achieve a higher reflectance or transmission readings, as incident light is conserved and directed toward the film.

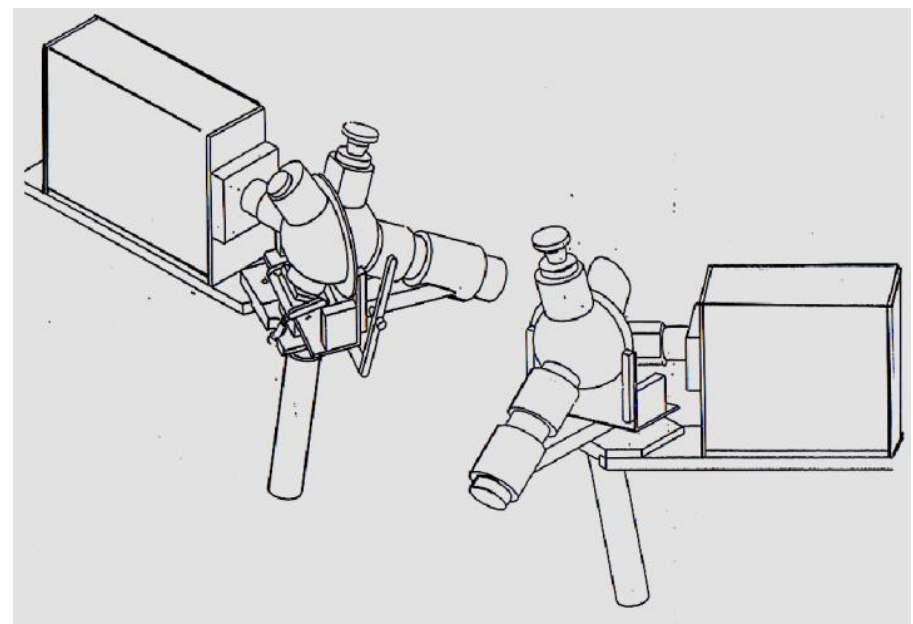

Figure 6. Spectron SE590 Spectroradiometer and LiCor Integrating Sphere (courtesy: Spectron Engineering). 
A follow-on crop cultivar study of greenhouse potted strawberries was begun in late January 2010, using the white plastic mulch over a CapMat II fertigation system ${ }^{\mathrm{TM}}$ (Hummert International, St. Joseph, MO), as shown in Figure 7. Capillary mats have become popular among wholesale and retail growers. The grower can easily fit the mat or fabric to the bench, place the plant pots on it and devise a simple watering system to keep the fabric saturated.

Twenty-four plants of each cultivar were selected based on number of leaves and size of plants. The experiment design was a randomized complete block design with six replications of four plants, three replications running North-South on each bench. Data taken included: date of first flower, total fruit number and berry weight per plant. Berries were deemed ripe based on color comparison between berries in the grocery store and those on the bench by using the RHS color chart. Greenhouse bees (Bombus impatiens) were introduced when the first flowers started to open. Within four weeks, some cultivars, resumed flowering and fruiting. Other cultivars were slower to respond. Mite infestations were controlled by spot spraying using organic-approved oil. Detailed results of this study will also be reported by Paparozzi, et al (2010).

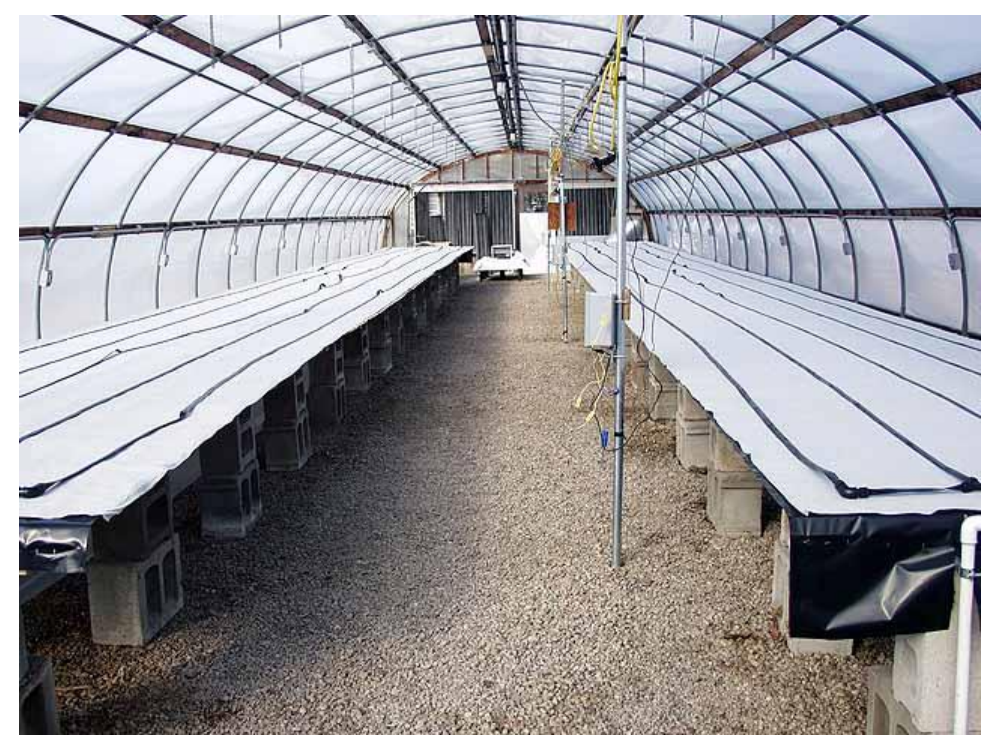

Figure 7. Setup of the CapMat II fertigation system. The black emitter strips are shown. The reflective mulch was placed over the CapMat fabric.

Six-inch pots were used, but a special hole cutting device was necessary to provide contact with the plastic mulch. Figure 8 shows the cutter board, which facilitated an even distribution of holes for the base of each pot. The pots were then in immediate contact with wet fabric under the mulch. Two benches (east and west) were used. 


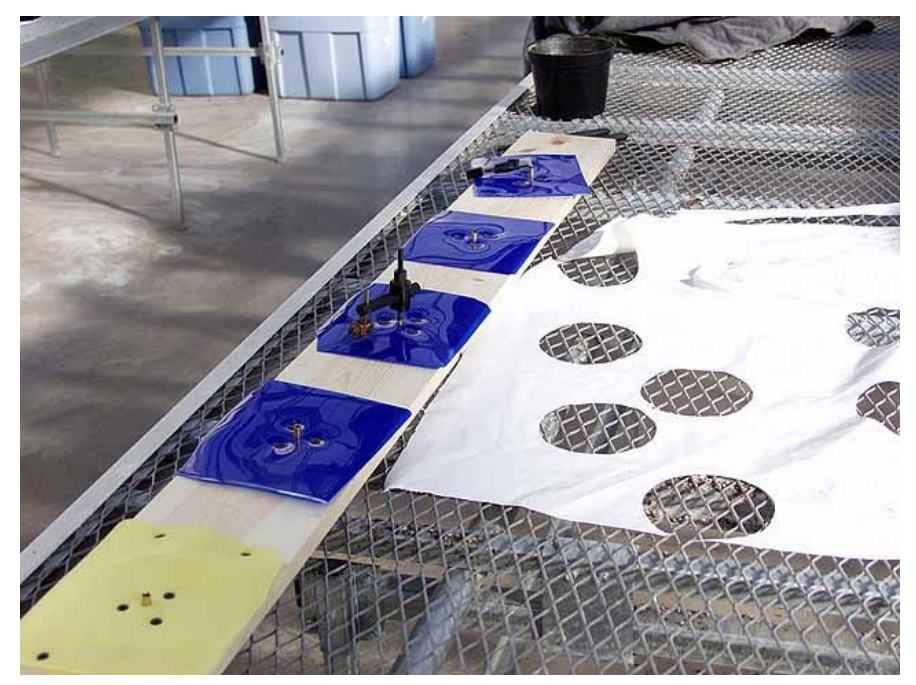

Figure 8. Cutter board system for producing holes in the plastic reflective mulch fabric.

Plants were fertigated with 100 ppm N from 20-20-20 commercial fertilizer for 5 minutes at every watering ( 2 or 3 times daily) using an Orbit irrigation controller (Bountiful, Utah ) and Dosmatic SuperDos 30 injector (Carrollton, TX). Three measurement zones (south, middle, and north) were set up with three WLS-TEMP loggers (Meyer, et al, 2009). These loggers recorded PAR, pot water content with EC-5 capacitance moisture sensors (Decagon Devices, inc., Pullman, WA) and a complete energy balance on respective potted strawberry plants. The EC- 5 soil sensors were calibrated to the medium used.

\section{Discussion and Results}

In terms of optical definitions, reflectivity and transmissivity refer to luminance by specific wavelength. Photosynthetically-active radiation (PAR) is based on peak of absorbance in the blue ( 500 nanometers) and red (650-750 nanometers), with considerable reflectance at 550 nanometers for a green leaf. Thus, plastics used as reflective mulches need to reflect large percentages in the blue and red wavelengths. Figures 9 and 10 show a summary of the average top reflectance and top transmittance of the reflective mulches using the Spectron SE 590 Spectroradiometer and integrating sphere. There was a slight difference in both the reflectance and transmittance relative to the thickness of the white film. White film tended to favor the visible wavelengths, especially in the blue for reflectance. Reflectance varied from 90 to 65 percent from near-infrared to blue, respectively. Thus, white films should provide significant reflected PAR energy when used as mulch.

Red mulches also provided reflected energy in the red and near infrared (20-30 percent), but less than half than with the white plastic and very little in lower wavelengths. The problem is that red also transmits a lot of red and near-infrared energy (as much as 60 percent); more so than with the white film (25-30 percent).

Olive and Black films reflected less energy (5-20 percent). The olive film had the highest transmission in the red and near-infrared (70-77 percent). Those films with lower reflectivity's and higher transmissivites might suggest higher absorption of thermal energy. However, this has yet to be confirmed. A study with several different films might be performed simultaneously to check energy entrapment performance in the greenhouse. 
Figures 11 and 12 summarize some of the data obtained with the PAR sensors in the greenhouse. The relative time is the number of LabVIEW seconds from the start of the scan. The zone numbers match the Front Panel in Figure 5b. This study was based on the concept of a reflectance coefficient. The reflectance coefficient is based on an average of the ratio of reflected PAR from the films or gravel to the incident PAR. This is not an energy conservative technique since the PAR sensors were only set up with a field of view (FOV) of one $\mathrm{m}^{2}$ of the reflecting surface. However, the field of view of the incident sensors was not constrained beyond the hemispherical design of the LiCor sensor. Because of its hemispherical nature, light energy could be measured not only from above but also from the side. Typically, natural lighting in greenhouses could affected by multiple reflections from the inside surfaces of the glazing, as well as transmission and solar angle effects. Consequently, percentages of reflectance coefficients could be quite different than from the integrating sphere method.

Figure 11a shows that the 6-mil white plastic has a reflectance coefficient of approximately 1015 percent. 4-mil white plastic not shown here was similar. However, the other films; red (Figure 12a), olive, and black (all 1-mil) reflected energy was almost undetectable at less than 2 percent. Gravel also reflected 2 percent PAR or less.

Figures $11 \mathrm{~b}$ and $12 \mathrm{~b}$ show surface temperatures for white and red film respectively, along with gravel. These data are currently inconclusive. The temperatures were confounded by latent heat exchange. It was noted that the films tended to trap moisture through condensation. It is also noted the night time cycling of the natural gas heating system. This night time cycling may affect latent heat and moisture entrapment, which has been seen as early morning rain in some Nebraska greenhouses that do not use ventilation to remove latent heat.

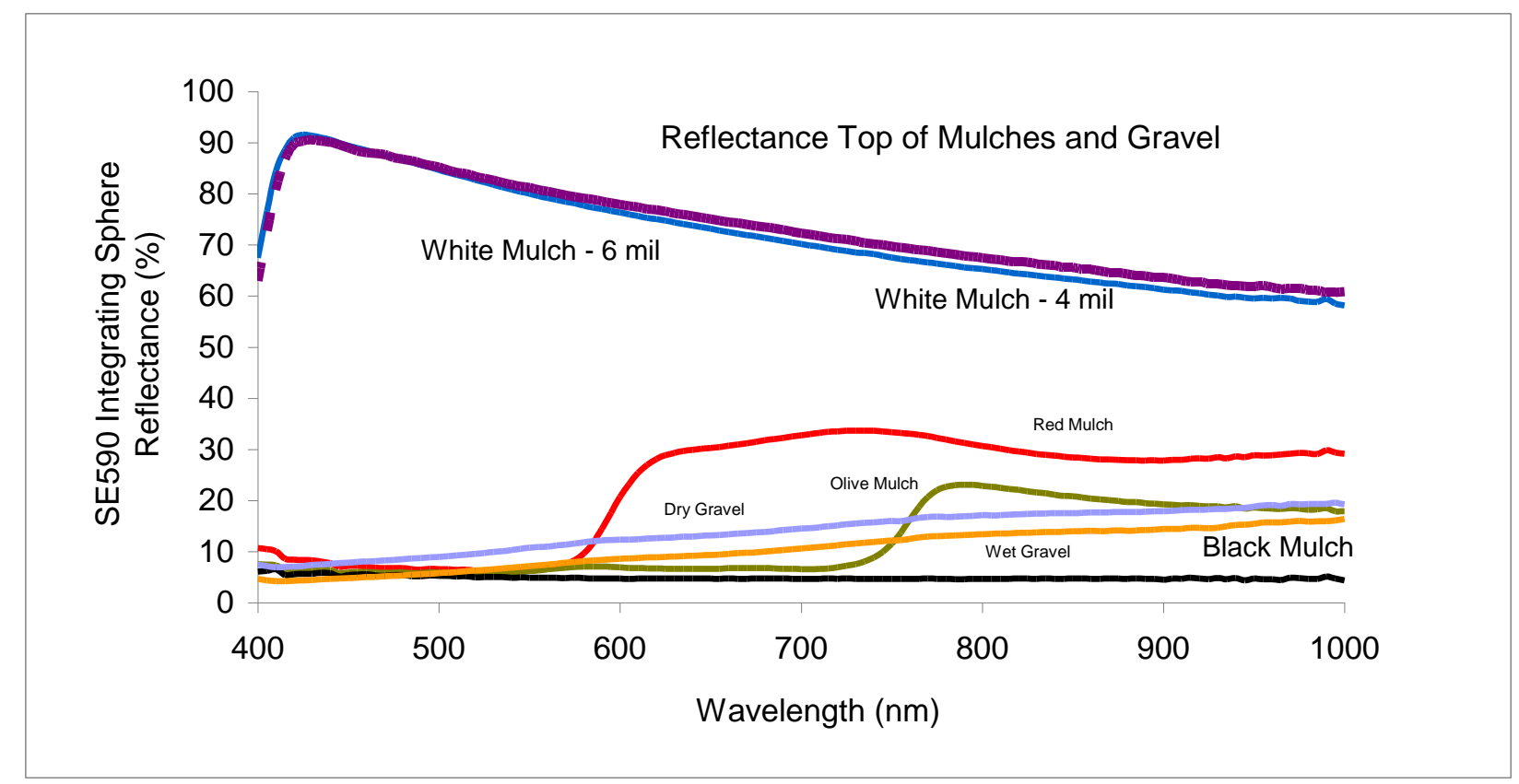

Figure 9. Integrating Sphere analysis of Plastic and Gravel Reflectance. 


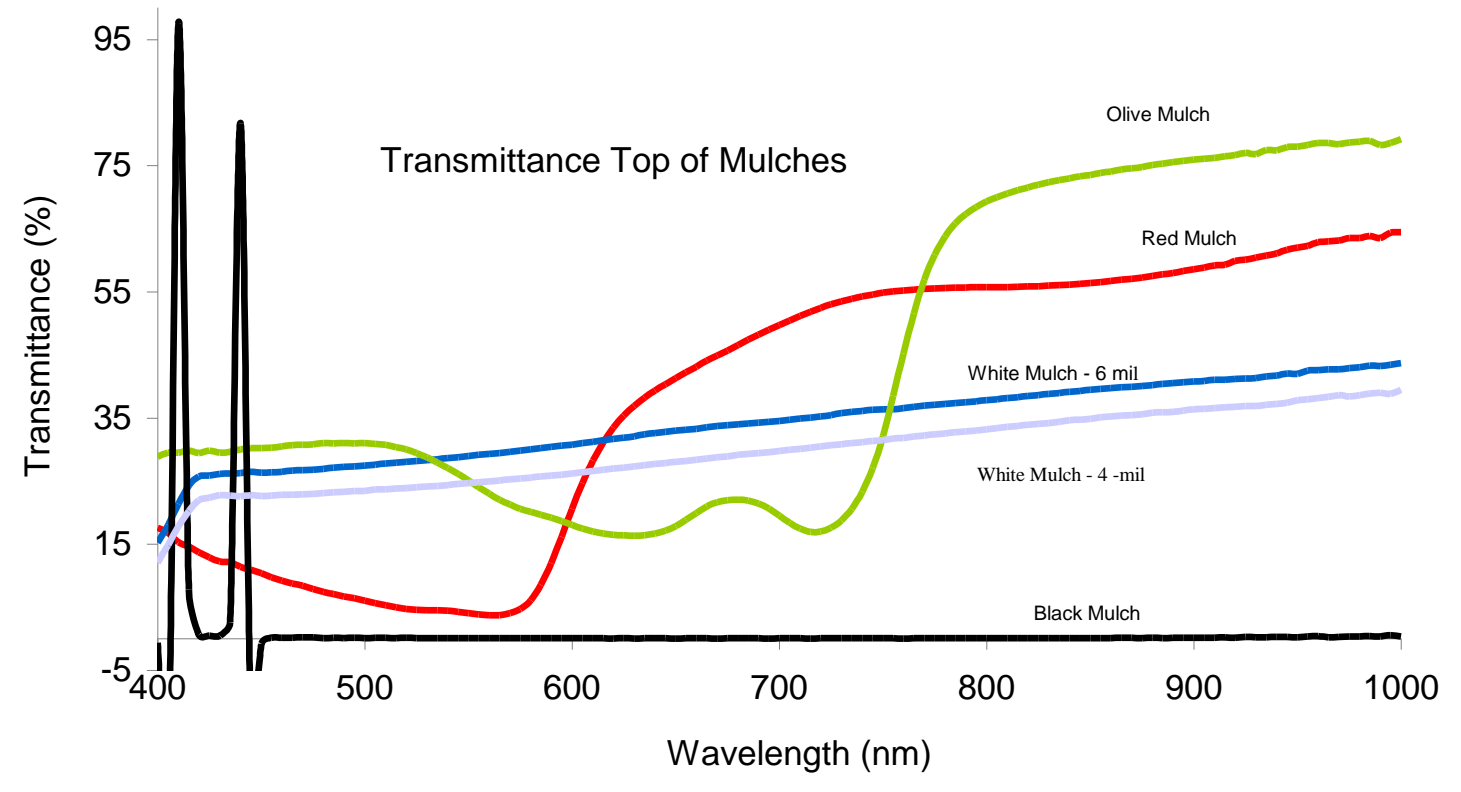

Figure 10. Integrating Sphere Analysis of Plastic Transmittance.

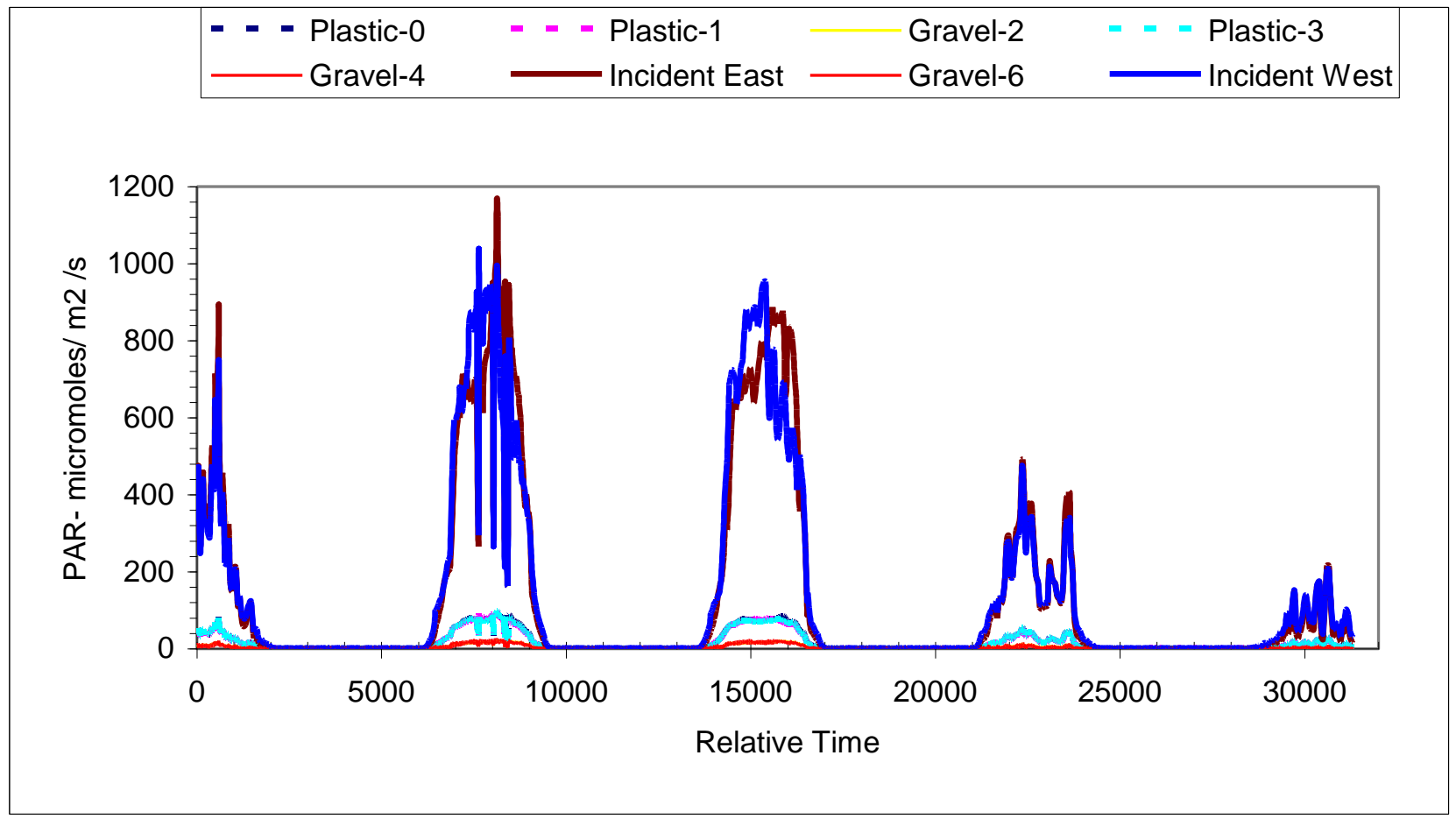

Figure 11a. Greenhouse reflectance's for 6-mil white plastic mulch. 


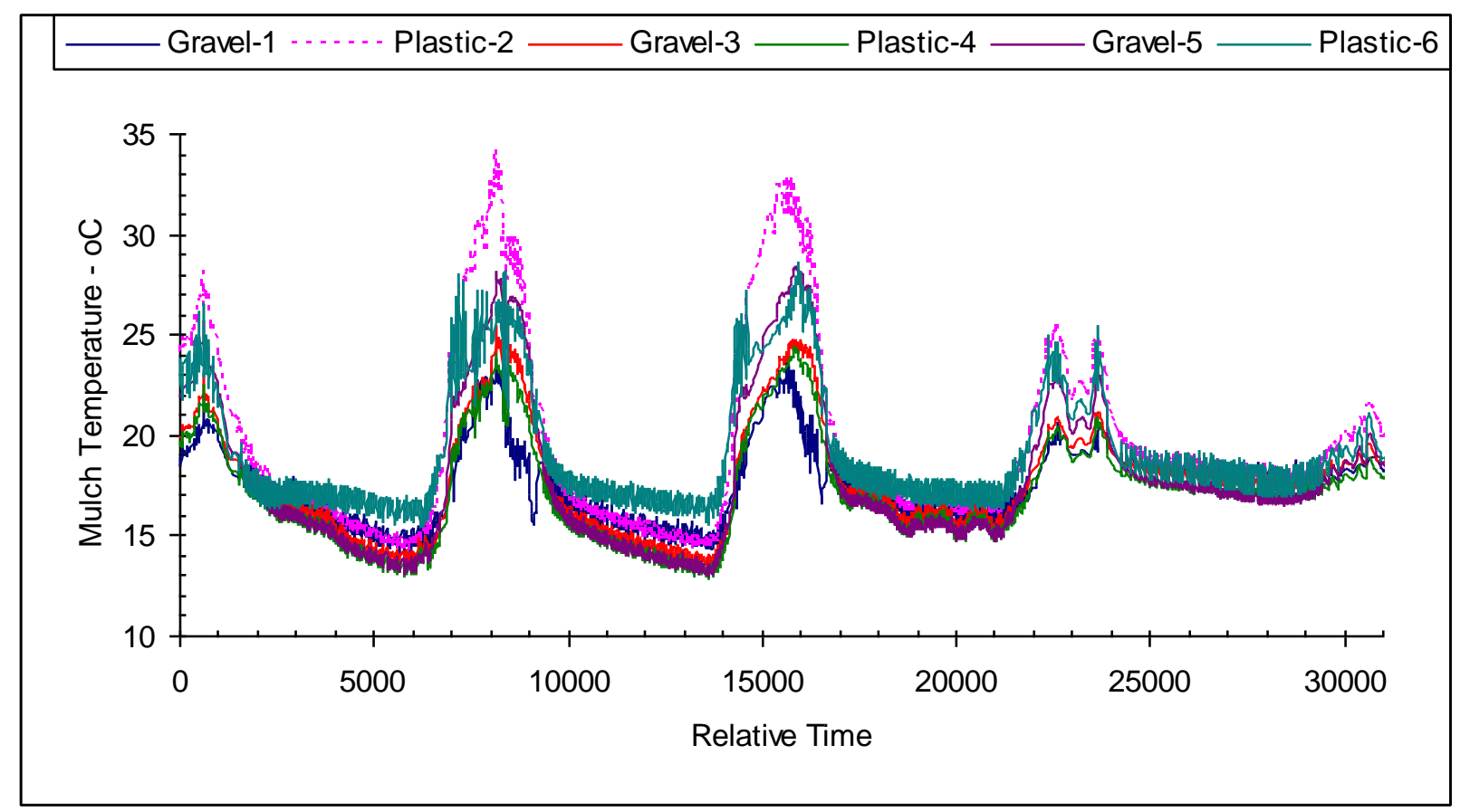

Figure 11b. White plastic (6-mil) surface temperatures by zone.

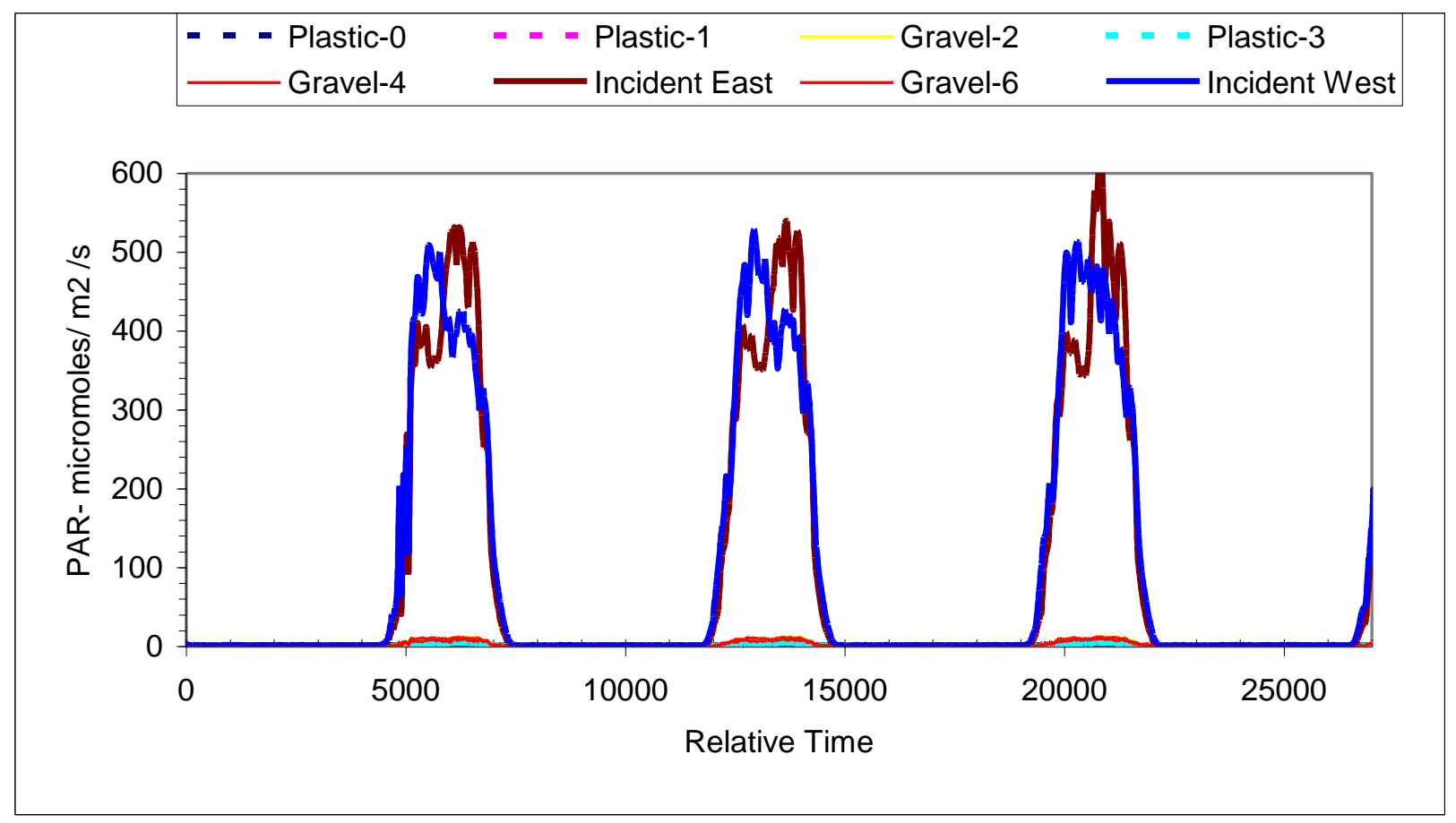

Figure 12a. Greenhouse reflectance for red 1-mil plastic film. 


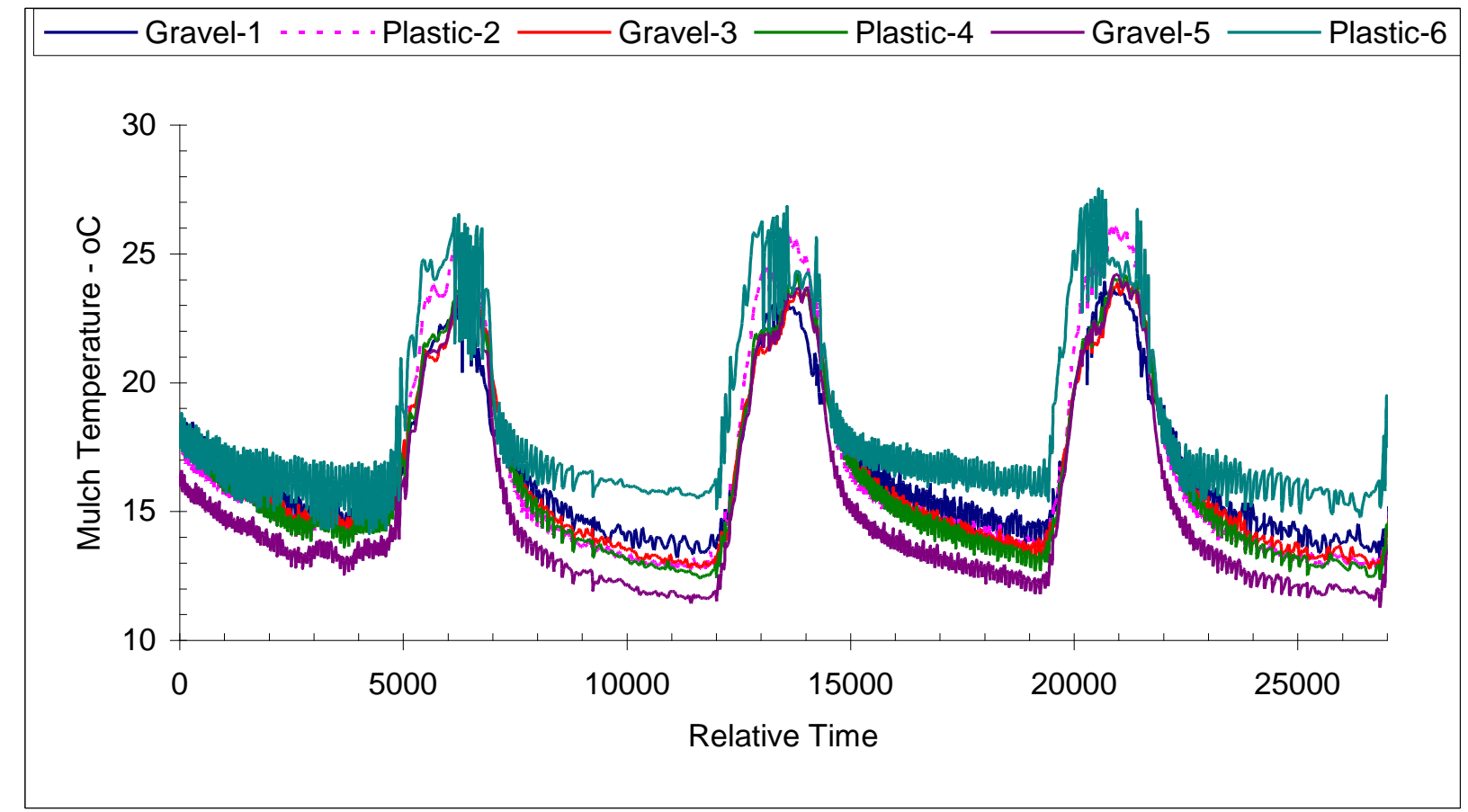

Figure 12b. Surface temperatures of 1-mil red plastic films.

Figure 13 shows the reflective mulch over the CapMat fabric for both the east and west benches. Zone loggers are shown in the aisle. These pictures were taken around the fourth month of the greenhouse cultivar study. Some of the plants are still bearing fruit, developing extended canopy growth, and starting to produce runners.
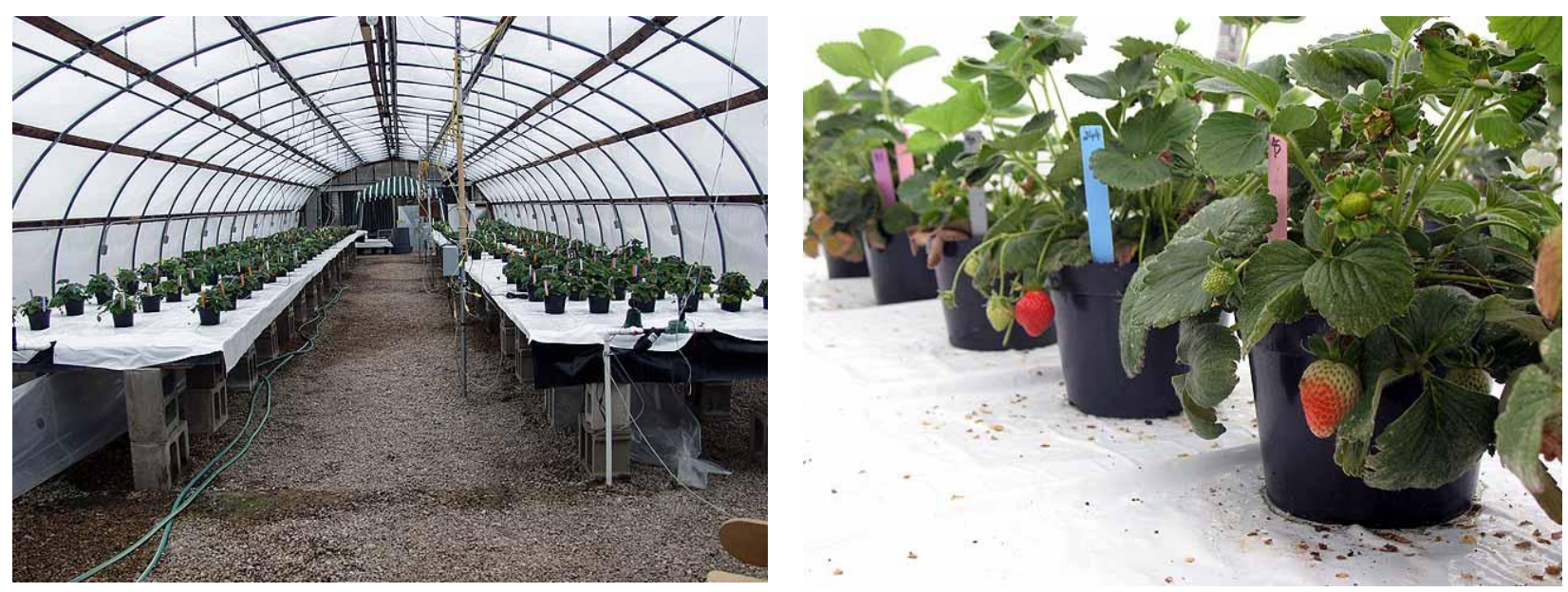

Figure $13 \mathrm{a}, \mathrm{b}$. Greenhouse strawberry study and production in operation with CapMat and white reflective plastic mulch. 
Figure 14 shows two and a half days of a times series of volumetric pot moisture contents for the three bench zones collected by LabVIEW. These data were for late April. The middle zone pots tended to be a little drier, possibly because of unevenness of the floor. Three fertigation events are shown for the photoperiod by the blips in moisture content. Overall, fertigation was adequate, but algal growth occurred on the CapMat fabric.
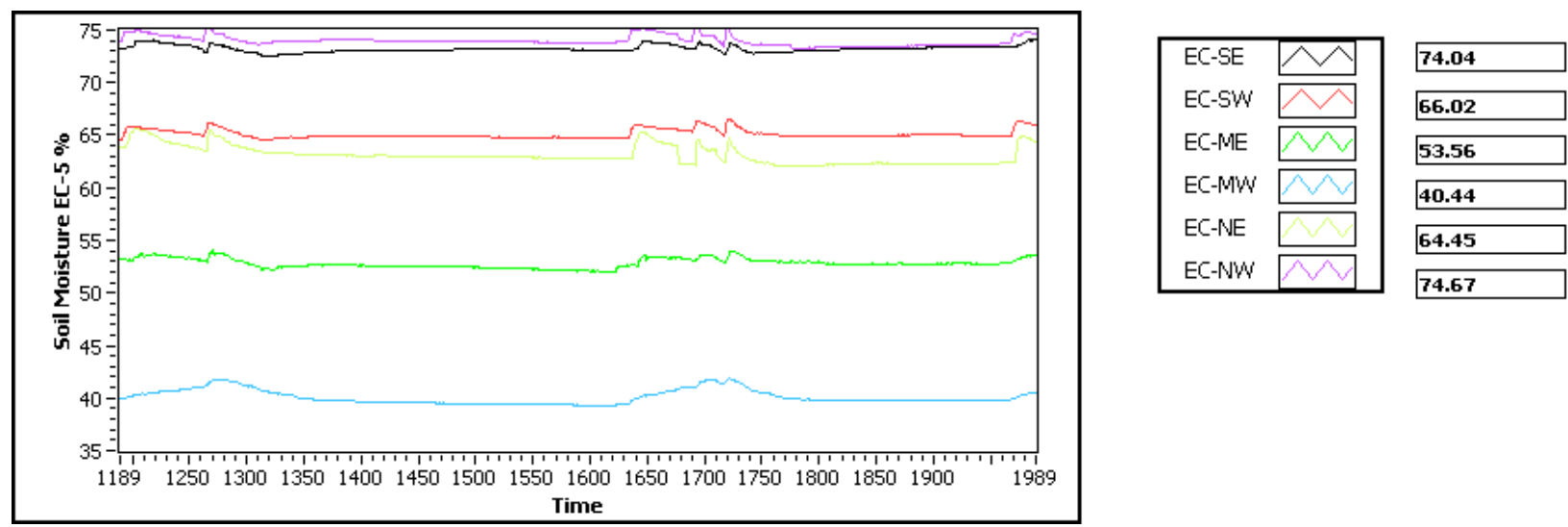

Figure 14. Volumetric water contents of six selected pots of strawberries. (SE-south-east, SWsouth-west, ME-middle east, MW-middle west, NE-north east, and NW-north west bench locations).

\section{Conclusions}

The white poly (4 mil) had the best PAR reflectance performance and was selected as the film and covering for the follow-up CapMAT strawberry variety trial. This second phase included growing strawberry plants on the capillary mats. During this phase, the strawberry plants performed well by producing numerous flowers and fruit. . This latter study showed that pots could be kept moist and that the mulch reduced evaporative loses from the fabric. The only problem noted was that some light penetrated the while polyethylene mulch and allowed algal growth on the CapMat fabric. This greenhouse study was successful and will continue.

\section{Acknowledgements}

Special thanks are given to Dr. Elizabeth Walter-Shea (School of Natural Resources) and her technician Mark Mesarch, who assisted with the spectoradiometer and integrating-sphere light studies. A thanks is also given to Mr. Gary Deberg (Biological Systems Engineering) who developed the polyethylene hole-cutting device. Mention of specific trade names is for reference only and not to imply exclusion of others that may be suitable.

\section{References}

2009. Comparison of Quantum Sensors with Different Spectral Sensitivities.

LiCor Biosciences. Technical Note \#126.

Csizinszky , A.A., D.J. Schuster, and J.B. Kring, 1995. Color Mulches Influence Yield and Insect Pest Populations in Tomatoes. J. Amer. Soc. Hort. Sci. 120(5):778-784.

Decoteau, D.R., M.J. Kasperbauer, and P.G. Hunt, 1989. Mulch Surface Color Affects Yield of Fresh-market Tomatoes. J. Amer. Soc. Hort. Sci. 114(2):216-219. 
Gough, R.E., 2001. Color of Plastic Mulch Affects Lateral Root Development But Not Root System Architecture in Pepper. Hortscience 36(1):66-68.

Greer, L. and J.M. Dole, 2003. Aluminum Foil, Aluminum-painted Plastic, and Degradable Mulches Increase Yields and Decrease Insect-vectored Viral Diseases of Vegetables. Hort Technology. 13(2):276-284.

Kasperbauer, M. J. and J. H. Loughrin, 2004. Morphogenic Light Reflected to Developing Cotton Leaves Affects Insect-Attracting Terpene Concentrations. Crop Sci. 44:198-203.

Meyer, G.E., D. Mabie, F.J. Hay, S. Adams, T. Bartels, and J.B. Fitzgerald, 2009. Improved Instrumentation and Controls for Biomass Heating and Impact on Greenhouse Profitability. ASABE Paper Number 09-096884. The American Society of Agricultural and Biological Engineering, St Joseph MI.

Paparozzi, E.T., S. Adams, G.E. Meyer, M. E. Conley, V. Schlegel, E. Blankenship and P.E. Read, 2010. Selecting Strawberry Cultivars for Winter Greenhouse Production. American Society for Horticultural Science Annual Meeting. Palm Desert, CA, HortScience, in press. 